\title{
RICARDO BAEZA Y LA DIFUSIÓN DE LA CULTURA EUROPEA EN ESPAÑA (1909-1936)
}

\author{
Eduardo Creus Visiers \\ (Università degli Studi di Torino)
}

Ricardo Baeza (Bayamo, Cuba, 1890-Madrid, 1956) es autor hoy algo olvidado pese a haber sido un intelectual de no escaso prestigio en los años veinte y treinta del pasado siglo, y un diplomático de cierto renombre en la España republicana. Baeza fue hombre de intereses muy variados, pero sintió siempre como vocación primordial la divulgación y la crítica de la cultura. Ambas las ejerció con brillantez, primero en España y luego desde el exilio, y a ambas consagró casi por entero su existencia. La traducción, la dirección teatral, la labor editorial, el ensayo y la crítica periodística fueron sus instrumentos. De esta diversificada actividad conocemos bien, gracias a los estudios especializados, sus contribuciones al mundo teatral español, por lo que en lo que sigue no me detendré en esas cuestiones. También su faceta de traductor empieza a ser bien apreciada. Este aspecto de su aportación tiene especial interés, porque Baeza no fue traductor profesional al modo de tantos otros de su tiempo, sino escritor atraído desde muy pronto por una actividad que reputaba imprescindible para que España alcanzara nivel cultural análogo al de los principales países de Europa. Sostuvo esta tesis en una serie de artículos publicados en el periódico El Sol en 1928', en los cuales afirmaba que, debidamente realizadas, las traducciones de los valores literarios europeos podían contribuir a que España se rescatase de la profunda decadencia a que los dos siglos precedentes la habían reducido. Conviene advertir aquí que Baeza no fue condescendiente, en los años de su afianzamiento como escritor y periodista, con las debilidades de la cultura española: menospreció sin contemplaciones buena parte de nuestras letras por juzgarlas de calidad escasa, útiles a lo sumo para adquirir mejor dominio

\footnotetext{
${ }^{1}$ «El espíritu de internacionalidad y las traducciones» (2 de octubre de 1928, p. 1), «Traduttore: traditore» (9 de octubre de 1928, p. 1), «El traductor como artista», (13 de octubre de 1928, p. 1), "Literalidad y literariedad» (26 de octubre de 1928, p. 1) y «La pérfida errata y el traductor sin imaginación» (15 de noviembre de 1928, p. 1).
} 
del idioma; le desagradaba casi toda la dramaturgia áurea y el entero siglo XVIII, y del XIX salvaba a Galdós, no sin reprocharle sus carencias, aunque resaltó los valores de nuestra tradición literaria y —lo que es más meritorio- acertó especialmente en la identificación de los nuevos. También en el enjuiciamiento de la europea le asistió su buen instinto crítico, del que dejó abundante huella en la prensa de los años veinte. Baeza se caracterizó por un ejercicio de la crítica literaria del que todo podrá decirse salvo que fuera contemporizador o timorato: no eludió la discusión o la abierta disputa (en realidad las propició en más de un caso) y defendió sus ideas con la eficacia del buen polemista.

Baeza teorizó sobre el modo adecuado de afrontar la traducción literaria, sosteniendo que no solo con el conocimiento de las lenguas, sino también con la posesión de suficientes competencias críticas y de una fina sensibilidad estética debía realizarse. Dudó de que pudiera hacerse del poema en otro idioma algo más que una paráfrasis y abogó, con argumentos que no andan lejos de los que después emplearían José Ortega y Gasset, Alfonso Reyes, Francisco Ayala, Octavio Paz o Jorge Luis Borges, por una traslación que podríamos definir «empática» con el autor traducido (él la llamó «obra de entusiasmo y fervor $\left.»^{2}\right)$, y consecuentemente fiel al espíritu del texto, a su belleza artística más que a la literalidad. Resaltó tanto el alto valor formativo de las traducciones para la sociedad española como la utilidad de su ejercicio para el hombre de letras. Convencido, como lo estaría siempre, de la necesidad de una internacionalización del saber, afirmó que las grandes obras literarias extranjeras no podían ejercer con plenitud su influencia en un país hasta que eran incorporadas a su idioma, aun cuando los lectores más instruidos tuvieran acceso a ellas sin necesidad de traducciones. Observó también que antes de la Primera Guerra Mundial la traslación en gran escala de los valores literarios de unos y otros países había sido escasa en Europa, con la salvedad de Alemania e Italia. Esta insuficiencia la atribuía en los casos de Inglaterra y Francia al excesivo nacionalismo cultural de ambos países, explicación que estimaba solo parcialmente válida para la circunstancia española. La mayor precariedad de nuestra cultura, el aislamiento de Europa y una connatural «desapetencia de civilización espiritual» ${ }^{3}$ eran causas más determinantes, en el caso hispánico, que la anteojera nacionalista y debían considerarse principales motivos de una deficiencia en materia de traducciones que solo hacia 1918 había empezado a paliarse. Desde esas fechas las cosas habían ido cambiando, y si de un lado los resultados eran aún medianos, el criterio selectivo endeble y el predominio de lo

\footnotetext{
2 «El traductor como artista», cit.

${ }^{3}$ «El espíritu de internacionalidad y las traducciones», cit.
} 
francés casi absoluto, de otro iba afirmándose una voluntad, que Baeza juzgaba muy saludable, de asomarse al exterior y ampliar las propias miras.

Los escritores a quienes Baeza tradujo son innumerables y entre ellos abundan los de primer orden (La Rochefoucauld, Diderot, Lautréamont, Maeterlink, Ibsen, Hebbel, Nietzsche, Croce, Pirandello, Conrad, Somerset Maugham, O'Neill o Greene, entre otros), pero tampoco escasean las singularidades. En una primera etapa, tradujo a autores de los que en España había poca noticia, como Lord Algernon, Saint-Pol-Roux o el poeta Hafid, de quienes publicó textos breves en las páginas de Prometeo, la revista fundada en 1908 por el político liberal Javier Gómez de la Serna y dirigida a partir de septiembre del año siguiente por su hijo Ramón, con quien Baeza había entablado amistad en los años en que ambos estudiaron en el Instituto Cardenal Cisneros de Madrid. Esas primerizas versiones, aparecidas entre 1909 y 1911, dieron a conocer a un jovencísimo Baeza como fino traductor en diversas lenguas — francés, inglés, italiano y portugués- - y asociaron su nombre a una especie de marca de calidad que la revista se encargó de subrayar. Junto a las de los raros, con toda probabilidad requeridas por el también joven director, comparecen ya versiones de escritores mucho más notorios, como Gabriele D’Annunzio y Oscar Wilde, ambos de capital importancia en la formación intelectual de Baeza. Precisamente es de D'Annunzio su primera traducción en volumen: se trata de la tragedia La ciudad muerta, que editorial El Trabajo publicó en Madrid en 1909. De 1911, año en que su colaboración con Prometeo se hace menos intensa, es otra versión publicada en volumen del autor italiano, Sueño de un atardecer de otoño, poema trágico, y de dos de Oscar Wilde: La balada de la cárcel de Reading y La casa del Juicio, todas a cargo de la madrileña Imprenta Helénica. De ambos escritores emprendería después la traducción de otras obras, además de llevarlos en cuidadas versiones a las tablas españolas durante la época en que se dedicó a la dirección teatral, y escribir sobre ellos artículos y prólogos notables. Sobre el primero puede destacarse el artículo, «Gabriel D'Annunzio y La hija de lorio», publicado en el cuarto número de la revista Cervantes en 1916 y reproducido al año siguiente, con pocas variantes, como prólogo a su traducción de La hija de lorio en Minerva (la editorial que Baeza había fundado en Madrid con los hermanos Calleja), y con cambios más sustanciales en la edición conjunta de La ciudad muerta y Sueño de una mañana de primavera que presenta, como primer volumen del teatro completo de D'Annunzio, Editorial Mundo Latino en 1929. Se trata de un estudio en que resalta Baeza las cualidades estéticas del autor, juzgado genio literario por excelencia, capaz de cultivar con igual maestría los géneros 
narrativo, poético, dramático o crítico. Una misma actitud positiva y entusiasta ante el mundo da, según Baeza, cohesión a esa obra plural y permite a su autor afrontar los aspectos más sombríos de la existencia sin desfallecimiento, en «frenética» celebración de la plenitud de la vida: actitud que lo aproxima a la formidable figura de Nietzsche. Y en efecto, ciertas analogías entre el espíritu de la obra de D'Annunzio y el pensamiento del filósofo alemán resultan significativas, aunque en este punto la argumentación de Baeza no queda enteramente libre de objeciones, pues si algunos de los vínculos señalados son bastante evidentes — la exaltación de la fuerza espiritual, el menosprecio de «la virtud que empequeñece» o el orgullo individualista, por ejemplo—, otros parecen más discutibles: así el «heroísmo», que en su vertiente patriótica y guerrera elevó el poeta italiano a la enésima potencia estética pero el pensador no reconoció como propio, o una «indiferencia por toda incomprensión» que estaba muy lejos de sentir Nietzsche, según puede corroborarse en la lectura de su correspondencia. En cualquier caso, Baeza sí señala entre ambos una muy sustancial diferencia: «D'Annunzio es también un artista para quien el mundo visible existe. La línea, el color, el gesto, el ademán, la voz de los seres, le interesan más que su alma recóndita. [...] No es un filósofo sino un artista $»^{4}$. El desarrollo de esta idea revela la fuerte inclinación esteticista de Baeza, que volveremos a encontrar en sus aproximaciones a la obra literaria de Oscar Wilde o a la de Gabriel Miró, pero que en modo alguno constituye un criterio excluyente, puesto que convive con un interés no menor por los valores éticos del arte; valores que, a su juicio, deben acompañar al ejercicio literario y en los cuales ahondará en sus diversas incursiones críticas en la novela rusa. En el teatro de D’Annunzio halla también Baeza concomitancias con los aspectos sustanciales de la tragedia clásica, y juzga La hija de lorio obra «de pura entraña dramática, desnuda, palpitante, sin afeites de retórica» y la de inspiración más cercana al mundo cristiano, pues en ella «convergen el alma antigua y el alma moderna, se funden la tragedia griega y el misterio medioeval $»^{5}$.

De mayo de 1926 es el folletón de El Sol titulado «La antorcha escondida», en que Baeza, que a sí mismo se define «introductor en nuestra escena de la obra de D'Annunzio», deplora una indiferencia del público español ante esta obra que no duda en considerar sintomática de muy graves deficiencias culturales. Aunque Baeza recuerda que La antorcha escondida tuvo recepción desigual en sus apariciones en la escena italiana, sostiene que no debe hacerse extensiva esa circunstancia a

\footnotetext{
${ }^{4}$ «Gabriel D’Annunzio y La hija de lorio», Cervantes, I, IV (noviembre de 1916), p. 8.

${ }^{5} / v i$, p. 28.
} 
todo el teatro del dramaturgo, pues las discusiones suscitadas por la figura de D'Annunzio en su país se han zanjado finalmente a su favor, y si en España hubo quien lo hizo víctima de una «balumba de vituperio y anatema» en nombre de «la moral, la sencillez y sabe Dios cuántas otras liendres», esa crítica ha ido apagándose ante la general aprobación. «La obra admirable del poeta —agrega— se nos aparece ya a la luz tranquila de la clasicidad, circundada, no de lucha, sino de fervor y examen ${ }^{6}$. En cuanto a la calidad artística de La antorcha escondida, sobre ella hay igual consenso: olvidadas ya las infelices circunstancias de su estreno en Italia, que tanto contraste ofrecieran con el precedente éxito de La hija de lorio e influyeran en la tibia valoración de la crítica, esta obra viene considerándose entre las cimas más altas del teatro de su autor. Baeza elogia en La antorcha escondida la arquitectura teatral, la fluidez de una acción que avanza con lógica perfecta y sin digresiones, la solidez de los personajes, la concisión de su estilo deliberadamente popular, cuya naturalidad no ha de ser tomada por crudeza. Mientras La hija de lorio era vista por Baeza como producto de una síntesis y una convergencia, la obra examinada en este artículo constituye a sus ojos la mejor aproximación moderna a la «tragedia griega pura», cumbre de un clasicismo que acierta a inspirarse en los modelos de la tradición literaria occidental sin incurrir en los riesgos de la imitación y el pastiche.

En cuanto a Wilde, el otro gran esteta objeto de sus veneraciones, Baeza se declaró su principal introductor y defensor en España, actitud que le costaría las punzantes ironías de Rafael Cansinos Assens en sus memorias, donde nuestro autor no es tratado con miramiento ${ }^{7}$. Al margen de las rivalidades entre ambos operosos traductores, que aquí poco interesan, lo cierto es que Baeza acertó a presentar a Wilde a una luz decididamente más favorable que la de otros críticos patrios indiferentes u hostiles. En este sentido es significativa la respuesta que dio a cierta condena literaria y moral expresada por Ramón Pérez de Ayala en dos folletones publicados en El Sol en diciembre de 1917. Baeza arremetió contra las algo incautas razones del eminente crítico en una serie de seis artículos que fueron apareciendo en el diario La Correspondencia de España durante el mes de febrero de 1918 bajo el título «Oscar Wilde y el señor Pérez de Ayala». Los argumentos allí empleados por Baeza son graníticos, como lo es su defensa del escritor irlandés, pero sobre todo sorprende el conocimiento exhaustivo de la bibliografía sobre el caso Wilde, por esas fechas ya muy abundante en Inglaterra, así como de las circunstancias en que el autor de la Balada de la cárcel de Reading transcurrió sus últimos años. Baeza demuestra una vez más no carecer de esa empatía por él mismo

\footnotetext{
${ }^{6}$ "La antorcha escondida», El Sol, 17 de mayo de 1926, p. 2.

${ }^{7}$ Cansinos describe su primer encuentro con Baeza en el epígrafe «Exquisitos» del primer volumen de La novela de un literato (Hombres, ideas, escenas, efemérides, anécdotas). Madrid: Alianza Editorial, 1996, pp. 426-430.
} 
juzgada necesaria para la traducción de una obra literaria, que es, en fin de cuentas, la que da acceso a la auténtica comprensión crítica.

No menos notable es su aportación al conocimiento de Wilde en dos folletones que El Sol le publica en septiembre de 1925. Ambos fueron precedidos por un artículo suyo, «In carcere et vinculis», aparecido en el mismo periódico el 21 de agosto, en el cual criticaba la traducción castellana del De Profundis realizada por la escritora Margarita Nelken y difundida con el poco afortunado título La tragedia de mi vida. Baeza censuraba que la obra no se hubiera trasladado del original inglés sino de la versión alemana de Max Meyerfeld, señalaba algunos errores y hacía extensivos sus reproches a otras traducciones de Wilde recogidas en los volúmenes de las Obras escogidas de Biblioteca Nueva, hechas estas a partir de malas versiones francesas. Con afán propagandístico nada insólito en sus escritos, anunciaba también la aparición inminente de una mejor traducción de la obra de Wilde en su propia editorial, Atenea (antes Minerva). Las razones de Baeza obtuvieron inmediata y contenida respuesta de Nelken y, aunque apenas dieron lugar a polémica, sirvieron de excusa para los dos folletones de El Sol publicados bajo el título «La historia del De Profundis» ${ }^{8}$. En ellos Baeza da cuenta de la aventura editorial del libro: se refiere a las gestiones de Meyerfeld para su parcial publicación en alemán, a la edición facsímil (también incompleta) del manuscrito en el Daily Mirror, a la propagación en la prensa inglesa de fragmentos inéditos a raíz del proceso Douglas-Ransome de 1913, y por último a la edición ya enteramente restaurada que presenta Robert Ross en Nueva York ese mismo año. En alarde de inveterada pasión por la disputa, Baeza menciona aquí sus artículos redactados siete años atrás contra el autor de Troteras y danzaderas, los cuales afirma haber enviado a André Gide, no para «rematar al señor Pérez de Ayala, a quien, aparte de la buena amistad que nos une, admiro sinceramente en lo que tiene de admirable ${ }^{9}$, sino para confirmar la opinión del escritor francés y constatar el ya enorme aprecio en todas partes por la obra de Wilde.

A cinco meses escasos de la aparición de estos dos espléndidos artículos, volverá Baeza a escribir sobre Wilde. El motivo es ahora la versión española del libro de Alfred Douglas Oscar Wilde y yo preparada por Cansinos Assens. En tres contundentes folletones de El Sol publicados entre enero y febrero de 1926 (titulado el primero «Oscar Wilde y yo» y los dos siguientes «Oscar Wilde y Lord Douglas»), Baeza sale de nuevo en defensa de un Wilde marcado por su íntimo drama, «pecado nefando, infortunio deplorable o simple accidente, según las maneras de ver» ${ }^{10}$, pero autor de

\footnotetext{
${ }^{8}$ La «Respuesta al Sr. Baeza» de Nelken apareció en la primera plana de El Sol el 24 de agosto de 1925. Los dos artículos titulados «La historia del De Profundis», en que Baeza replica a Nelken, se publican en el mismo periódico los días 2 y 3 de septiembre de 1925.

9 "La historia del De Profundis», El Sol, 3 de septiembre de 1925, p. 6.

10 «Oscar Wilde y yo», El Sol, 27 de enero de 1926, p. 5. 
irreprochable honestidad, de inteligencia y profundidad psicológica encomiables, y de una maestría literaria que ninguna circunstancia biográfica puede ofuscar. Baeza, tan competente en la diatriba como en la apología, se sirve de estas notas iniciales para rebatir con mayor eficacia la imagen de Wilde que quiso legar a la posteridad Lord Douglas con un libro mezquino que nunca debió haberse traducido al castellano. Demuestra luego, cotejando algunas partes, que esta versión se ha hecho a partir de la francesa, contra lo que el propio Cansinos declara en el volumen, y reprueba que hasta las notas del traductor sean las de esa edición, pero sobre todo censura la inclusión de un «indigno» prefacio de Lord Douglas a la versión española, así como la mediocridad de un prólogo, este del traductor, que revela absoluto desconocimiento en la materia. Baeza desmonta punto por punto el insustancial panegírico que hace Cansinos de Alfred Douglas y pone en solfa, con información biográfica pormenorizada, conjeturas tan infundadas como la de una influencia literaria del aristócrata en Wilde. Con igual rigor denuncia las falsedades del prefacio de Lord Douglas e informa a los lectores españoles de las vicisitudes legales que propiciaron la difusión íntegra de la célebre epístola In carcere et vinculis y desvelaron las miserias del aciago amante de Wilde. También estas páginas, suscitadas — como las escritas a propósito de las ideas de Ramón Pérez de Ayala o de la traducción de Margarita Nelken — por ardores polémicos no exentos de intención propagandística, son muestra del rigor documental propio de su mejor prosa crítica.

No menos notoria fue la controversia que brevemente mantuvo Baeza con Eugenio D'Ors sobre Sei personaggi in cerca d'autore tras el estreno de esta obra en diciembre de 1923, en el teatro Princesa de Madrid y a cargo de la compañía de Dario Niccodemi. Aquel acontecimiento cultural generaría animados debates en España, a los que Baeza tuvo ocasión de contribuir con una conferencia, leída en la Residencia de Estudiantes el 8 de enero de 1924, en que manifestaba sus discrepancias con las ideas de $\mathrm{D}^{\prime}$ Ors sobre la obra, expuestas estas en el diario $A B C$ a fines de diciembre del año anterior ${ }^{11}$. Para $\mathrm{D}^{\prime}$ Ors la singularidad del drama pirandelliano había consistido en su facultad de mostrar a plena luz el conflicto del creador frente a sus criaturas en cierne, el ímprobo esfuerzo que supone dotar a esos ficticios entes de la coherencia interna que desde el primer instante exigen de quien los concibe. En la obra de Pirandello se dramatizaba ese proceso, trasladándolo «desde el campo de conciencia del creador inicial hasta el dominio público» e incurriendo así en lo que bien podía considerarse un ejercicio de «falsedad metafísica» ${ }^{12}$. A juicio de Baeza, esta

\footnotetext{
${ }^{11}$ Eugenio D'Ors: «La particularidad de la comedia de Pirandello», ABC, 26 de diciembre de 1923, pp. 15-16. El texto de la conferencia lo resumió el propio Baeza en un folletón de El Sol (del 17 de enero de 1924) y lo recogería más tarde, en versión completa y bajo el mismo título ( «Seis personajes en busca de autor»), en su libro En compañía de Tolstoy, seguido de otros motivos e indicaciones (Madrid: Renacimiento, Compañía Ibero-Americana de Publicaciones, 1932, pp. 157-191).

12 «La particularidad de la comedia de Pirandello», cit., p. 16.
} 
interpretación de D’Ors — en todo momento aludido elípticamente como «el sutil glosador»— más que aclarar las cosas había venido a aumentar la confusión sobre una obra ya de por sí espinosa. No le parece a Baeza que interpretarla como «el drama del creador esclavo de las criaturas de su invención $»^{13}$ sea el modo más adecuado para apreciar su particularidad, y juzga preferible poner el acento en la «realidad fantasmal de los seis personajes», en su problemática existencia como entes de ficción. Un somero análisis del drama pirandelliano basta, según Baeza, para constatar que los personajes que por él deambulan ya no parecen obsesionar la mente de su creador: han quedado abandonados, probablemente a medio hacer, como a medio hacer quedó la trama en que hubieran podido cobrar sentido. La que presenciamos no es aquella para la que fueron concebidos, sino su suspensión o su aborto. El drama se nos revela entonces como tentativa de reflexión sobre los límites entre el mundo real y el imaginario, y sobre la imposibilidad de precisarlos. Es este un problema cuya filiación filosófica encuentra Baeza en el pensamiento sofístico más que en el escéptico, aunque no ha de ir tan lejos para determinar la artística, pues la obra pirandelliana le permite establecer analogías con otras contemporáneas de su mismo linaje, como la Petrushka de Igor Stravinsky — parangón que merecería luego la ironía de $\mathrm{D}^{\prime} \mathrm{Ors}{ }^{14}$ - o El señor de Pigmalión de Jacinto Grau. También en estas se nos impone la realidad conflictiva de sus entes ficticios, bien que carente en ambas de la sombría trama psicológica, dostoievskiana, de los seis personajes de Pirandello, que viene a entreverarse con el problema de su ingrávida esencia artística. Y es precisamente en los insólitos efectos resultantes de vincular el abstracto drama de la realidad fantástica de los personajes con el de la «ficción humana» donde radica la originalidad de la obra pirandelliana. «Los personajes — observa Baeza — se nos muestran sin el menor rebozo, ahincados en descubrirnos sus más recónditos motivos e impulsos; y cada uno nos presenta el drama desde su punto de vista ${ }^{15}$, artificio que abre espacio a la experimentación y nos permite asistir como espectadores al crudo examen del armazón en que se sostiene el drama, al desmontaje del mecanismo psíquico de la acción, a la vivisección más implacable. D’Ors había concluido sus razones emitiendo una seria objeción contra el drama pirandelliano: «en esta obra singular y poderosa, ¿hay una realidad, hay siquiera un camino de esperanza para el teatro? ¿Podremos escribir, podremos ver otras obras en este camino?» ${ }^{16}$. Tanto rebuscamiento en la originalidad dramatúrgica, se preguntaba D'Ors, ¿no oculta, tras la aparente fuerza, impotencia y límite? La discrepancia de Baeza también es aquí enérgica: Pirandello, maestro

\footnotetext{
13 "Seis personajes en busca de autor», El Sol, 17 de enero de 1924, p. 2.

${ }^{14}$ En su glosa «Defensa e ilustración de los críticos teatrales», $A B C, 24$ de enero de 1924, p. 4.

15 «Seis personajes en busca de autor», cit., p. 2.

${ }^{16}$ «La particularidad de la comedia de Pirandello», cit., p. 16.
} 
en el empleo de los más eficaces resortes dramáticos y novelescos, ha construido una obra que «quizás no sea de una claridad meridiana» porque más que al entendimiento apela a nuestra intuición, «a nuestra facultad de percibir ideas y sentimientos aún embrionarios y por elucidar en la conciencia ${ }^{17}$, pero con esta obra misteriosa, laberíntica, de trama sutilísima y casi evanescente, ha logrado apartarse de las limitaciones del realismo propio del teatro moderno para ofrecernos el anuncio de su renovación en formas inéditas de la realidad fantástica. Con este reconocimiento del valor de la obra pirandelliana terminaba la conferencia de Baeza, la cual fue, con la versión de El hombre, la bestia y la virtud, apólogo en tres actos (publicada con la comedia La razón de los demás en 1924), su aportación a una fulgurante celebridad del autor italiano en España que quizá no llegara a ser influencia artística perdurable para la dramaturgia patria, pero sí suscitó vivaces debates intelectuales en torno a las fechas del estreno en nuestros teatros de Sei personaggi in cerca d'autore.

En la década de los veinte publican las editoriales españolas buena parte de la obra ensayística de Herbert G. Wells vertida al castellano: por entonces se reeditan libros como Anticipaciones, La humanidad tal cual es o El porvenir de América, que llevan ya años circulando impresos, y se traducen nuevos ensayos: Rusia en las tinieblas, El salvamento de la civilización, Esquema de la historia o La conspiración franca, entre otros ${ }^{18}$. No debe sorprendernos el interés por los ensayos de Wells, por esos años muy leídos gracias a la celebridad de su obra narrativa, publicada en la prensa de toda Europa y comúnmente presentada como novela científica. La enorme fortuna editorial de aquellas representaciones de un difuso fatalismo en relación con el porvenir de la sociedad humana había favorecido este interés por la prosa ensayística de su autor, en la cual alentaban análogas inquietudes sociales y políticas. Los ensayos wellsianos denuncian riesgos para el porvenir de la humanidad y participan del mismo desaliento de sus ficciones, pero, a diferencia de estas, no pueden ofrecer desenlaces más o menos confortantes y deben limitarse a propugnar soluciones utópicas a los desastres en curso o en potencia. El deus ex machina que en la ficción alcanza a resolver de algún modo el conflicto, en el ensayo se enuncia con la fragilidad de lo condicional y lo incierto. De ahí que por inquietantes que resulten sus narraciones, el examen de la realidad que el ensayo nos presenta acaba siendo mucho más alarmante. Aquellas alarmas las compartía también Ricardo Baeza en los años en que resolvió traducir algunos de ellos.

\footnotetext{
17 «Seis personajes en busca de autor», cit., p. 2.

18 Anticipaciones y La humanidad tal cual es, traducidos al español en 1905, y El porvenir de América, publicado en 1908, se reeditan en 1921 a cargo de la barcelonesa editorial Bauzá. En los años veinte aparecen, en traducción de Ricardo Baeza, Rusia en las tinieblas (Madrid: Calpe, 1920), El salvamento de la civilización (Madrid: Calpe, 1921), Esquema de la historia (Madrid: Atenea, 1925) y Paz o guerra: un examen de la situación internacional y del porvenir del mundo (Madrid: Atenea, 1927). Además, en 1929 Aguilar presenta los ensayos La conspiración franca: planes para una revolución mundial en versión de Cansinos Assens y Cómo marcha el mundo, de traductor desconocido.
} 
En los primeros meses de 1921, como corresponsal de El Sol en Londres, Baeza se encargó de las crónicas sobre actualidad política del Reino Unido y en especial de las tormentosas negociaciones posbélicas entre Alemania, Inglaterra y Francia. En sus artículos se mostró particularmente pesimista ante el riesgo de un nuevo conflicto armado de magnitud no inferior al de 1914: «Es muy posible —escribía el 8 de marzo- que estemos al comienzo de una nueva era de calamidades. El espíritu de Europa no es en verdad un espíritu de paz» ${ }^{19}$. A ello se sumaba la inestabilidad interna de una Rusia soviética en proceso de afianzamiento y la desestabilización provocada por los nacionalismos emergentes de la India y Egipto, y por los avances de una carrera armamentística en trance de convertir al Japón en gran potencia militar. «Cuando se piensa en lo que la última aventura guerrera ha costado a la humanidad y a la civilización — decía en otro artículo del mismo mes—, parece monstruoso conjeturar siquiera la posibilidad de otro cataclismo semejante o mayor», «el hombre crítico y dado al futuro se siente dolorosamente perdido en el Laberinto ${ }^{20}$. Rusia en las tinieblas, ¿Paz o guerra? y El salvamento de la civilización, los ensayos de Wells que por entonces traduce Baeza, son tentativas de afrontar el riesgo de una posible disolución social de la realidad europea. El primero de ellos, un vívido reportaje de Wells sobre su viaje a la Rusia soviética publicado en noviembre de 1920 en el Sunday Express, fue apareciendo en esos mismos días en una puntual y casi íntegra traducción de Baeza para su periódico. En la «nota preliminar» a la versión en volumen que Calpe publicó ese año, donde se recogía también el capítulo que había quedado sin traducir en las páginas de El Sol, subrayaba Baeza la relevancia del escrutinio de la realidad soviética que Wells había realizado en su reportaje, el cual debía considerarse ante todo «una severa condenación de los métodos maximalistas y un apasionado socorro a la causa de la civilización en Rusia». Esta percepción crítica, realista y poco entusiasta del sistema soviético, al que a juicio del escritor británico convenía que auxiliasen las potencias occidentales porque ningún otro podría sustituirlo y porque su eventual desmembramiento afectaría a grandes regiones de Oriente y Occidente, Baeza la compartía en líneas generales, y tendría oportunidad de constatarla año y medio después sobre el terreno, con ocasión de su viaje a las regiones del Volga devastadas por la hambruna. Igualmente tempestiva fue la traducción que hizo Baeza de las reflexiones de Wells sobre la Conferencia de Washington de 1921 para la reducción de armamento. El Sol la publicó desde noviembre de ese año — pocos meses antes de la primera visita de Wells a España - en varias entregas y bajo el genérico título ¿Paz o guerra?,

\footnotetext{
${ }^{19}$ "Aliados hacia el Rin. Notas de la conferencia», El Sol, 17 de marzo de 1921, p. 1.

${ }^{20}$ «Malos presagios», El Sol, 25 de marzo de 1921, p. 1.
} 
aunque su aparición en volumen fue más tardía. De mediados del mismo año es su versión de $E I$ salvamento de la civilización publicada primero en El Sol y luego en volumen por la editorial Calpe: una serie de textos programáticos en que abordaba Wells el análisis de la situación general del mundo y teorizaba sobre la constitución de un Estado mundial y un orden nuevo capaces de neutralizar las amenazas del convulso momento histórico. No es preciso detenerse aquí en el examen del singular credo wellsiano; baste señalar que la sugestión de aquellas ideas — como también la del pensamiento libertario kropotkiniano- alimentó cierto idealismo utópico que puede notarse en algunos escritos de Baeza, y que este trasladó, con entusiasmo y convicción característicos, a las primeras planas de uno de los periódicos por entonces más influyentes en la opinión pública española.

De 1926 es su traducción del segundo tomo de The Outline of History, del cual había aparecido ya el primero, a cargo de Enrique Díez-Canedo y bajo el título Esquema de la historia, en Atenea (esta versión se reeditaría más tarde, y en diversas ocasiones, en Argentina y México, desde que en 1947 la editorial Anaconda la publicara en Buenos Aires). La aparición del Esquema en España dio lugar a una nueva polémica, promovida esta vez por Salvador de Madariaga y en la que medió Eduardo Gómez de Baquero. En «Escepticismo histórico», publicado en El Sol en septiembre de 1925, Madariaga había expresado sus reticencias sobre el internacionalismo del escritor británico, definiendo su obra un «noble fracaso». Baeza respondió con otro artículo, del 21 de ese mismo mes, titulado precisamente «El internacionalismo de Mr. Wells», en el cual rechazaba que las influencias anglosajona y protestante fueran las definitorias del libro y elogiaba tanto la objetividad de Wells como su tesón en defensa de la paz mundial y la creación de un Estado Federal del mundo que pudiera superar todos los localismos. En marzo del año siguiente, a poco de publicarse en Atenea su traducción del segundo volumen de The Outline of History, intervendría de nuevo con tres artículos, en que se hacía eco de los elogios de Andrenio al libro, expresados estos en sendas reseñas para EI $\mathrm{So}^{21}$. En la primera de ellas, Andrenio había valorado la obra de Wells por sus virtudes historiográficas más que por la intención trascendente, y en la segunda elogiaba el esfuerzo intelectivo del autor y el punto de vista adoptado, sin desdeñar la visión profética de Wells que cierra el libro. A esta segunda reseña alude Baeza, porque es la que concierne al tomo por él traducido. Confirma las cualidades advertidas por Andrenio, a las que suma otros méritos: la capacidad de síntesis, el ameno didactismo y, sobre todo, una formidable amplitud de perspectivas.

\footnotetext{
${ }^{21}$ Los tres artículos de Baeza en El Sol son: «Un libro formativo» (15 de marzo de 1926, p. 1), «Un libro informativo. El Esquema de Mr. Wells» (22 de marzo de 1926) y "Un libro formativo. El Esquema de Mr. Wells» (29 de marzo de 1926). Gómez de Baquero había reseñado las dos partes del Esquema de la historia en «El panorama de la historia» (30 de abril de 1925 , p. 1) y «Pasado y futuro» (11 de febrero de 1926, p. 1).
} 
La experiencia como corresponsal de El Sol en Gran Bretaña, entre el verano de 1920 y marzo de 1922, había dado a Baeza oportunidad de ahondar en su conocimiento de las letras inglesas, sobre las cuales seguiría escribiendo a lo largo de su vida y en las que, según declaración propia, estaban algunas de sus mayores devociones: Shakespeare, Milton, Coleridge, Shelley, Poe, Wilde, Wells, al que conoció por esas fechas, o Bernard Shaw, a quien pudo visitar en su domicilio londinense $\mathrm{e}^{22}$. Esta importante etapa de su vida fue precedida por una breve estancia en París no menos provechosa: en junio de 1920 escribe todavía desde la capital francesa —El Sol lo presenta como «enviado especial de paso hacia Inglaterra»-y es por entonces cuando tiene ocasión de observar en plena actividad al movimiento dadaísta y ponerse en contacto con su venerado André Gide y con el también admiradísimo André Suarès. En otro lugar he tratado con algún detenimiento la actitud de Baeza ante las vanguardias, por lo que solo señalo aquí que la intolerancia que hacia ellas muestra, aunque coherente con sus postulados teóricos, constituye una limitación, acaso la más seria, a su visión crítica de la modernidad literaria ${ }^{23}$. Y ello pese a que el propio Gide —en todos sentidos un modelo para Baeza - había comprendido el valor innovador del dadaísmo, a cuyos promotores juzgó en cierto momento la única juventud literaria con talento en Francia. Viniendo de un escritor como Gide, tal apertura desconcertaba a Baeza, bastante menos complaciente con una anarquía artística que vulneraba todos los presupuestos de su clasicismo en materia literaria. Sobre todo porque aquella actitud se había gestado principalmente en la lectura de los textos críticos del autor francés, determinantes en las tesis que Baeza sostendría en 1927 en su ensayo Clasicismo y romanticismo: una diatriba contra la estética romántica y sus excesos, y una apasionada declaración de fe en la dimensión ética de la literatura ${ }^{24}$.

Gide y Suarès son para Baeza los dos talentos franceses más sobresalientes del momento. El primero constituye una influencia intelectual muy poderosa en sus escritos críticos: determina sus ideas sobre la traducción y su interpretación de Dostoievski o Wilde, y bien puede definirse Clasicismo y romanticismo un vivaz diálogo con el autor de Prétextes. La menor celebridad de Suarès en España hacía precisa una presentación al lector, cometido que cumplió Baeza valiéndose de sus mejores

\footnotetext{
${ }^{22}$ Sobre la entrevista con Wells en «su campesino retiro de Easton Glebe», Baeza recoge dos textos en su libro Comprensión de Dostoiewsky y otros ensayos (Barcelona: Juventud, 1935). Aparecen bajo los títulos: "Una visita a Mr. Wells» (pp. 104108) y «Estética y civismo» (pp. 109-111), fechados el primero en septiembre de 1920 y el segundo en julio de 1921. El encuentro con George Bernard Shaw lo cuenta Baeza en «Bernard Shaw íntimo», de mayo de 1925, también recogido en Comprensión de Dostoiewsky (pp. 95-103).

${ }^{23}$ De ello hay numerosas muestras en sus escritos: rara es la ocasión que Baeza no aprovecha para condenar una estética que considera derivada de los peores excesos del romanticismo. Véase especialmente su artículo "La literatura dadaísta», publicado en El Sol en los días 24 y 27 de junio de 1920 (pp. 1 y 9 respectivamente), luego recogido bajo el título «Dadá» en Comprensión de Dostoiewsky (pp. 232-239).

${ }^{24}$ La mayor parte de los artículos que conforman Clasicismo y romanticismo aparecieron en El Sol entre junio y julio de 1927. La Compañía Ibero-Americana de Publicaciones los editó en volumen en 1930, fecha del centenario del estreno de Hernani.
} 
recursos: la traducción y la crítica. De 1916 es su versión de Don Quijote en Francia para Atenea, y de 1919 y 1920 la de algunos ensayos de actualidad que Suarès había reunido en Remarques y Baeza publica bajo el título «Observaciones» en el semanario España. La información sobre Suarès en el prólogo a Don Quijote en Francia es escasa: Baeza lo ignora casi todo del ensayista, pero afirma haberlo reconocido a través de sus obras como una de las mayores inteligencias del país vecino. El desconocimiento queda de algún modo justificado en la actitud esquiva de Suarès; una propensión al apartamiento que no le ha impedido escribir desde el compromiso más decidido con la causa francesa en la contienda europea en curso. La ubicación de Suarès en la generación de 1900, nacida en el rescoldo del simbolismo, y la asociación de su nombre con los de Gide y Claudel sirven para una escueta filiación literaria, a la que Baeza agrega, a modo de cierre de estas páginas liminares, la lista de sus publicaciones, ninguna de ellas traducida al español. Son datos escasos, pero bastan para poner de manifiesto un interés por la obra de Suarès que en Baeza fue muy vivo (bien que no lograra hacerlo extensivo a los lectores españoles, si ha de juzgarse por la escasa popularidad que alcanzó este escritor en España). En la primavera de 1920, Baeza pudo entrevistarlo en su casa del Barrio Latino, en París. «Una visita a André Suarès», texto fechado en julio de ese año, narra el encuentro y la animada conversación sobre actualidad literaria española, sobre política europea y también acerca de temas más íntimos, concernientes a la elección de Suarès de una vida apartada de lo mundano y lo académico, y a sus proyectos literarios. Pocas páginas bastan a Baeza para ofrecernos una vívida imagen del escritor, su aspecto físico, sus ademanes y opiniones, sus preferencias literarias y pasiones de bibliófilo. Tras la cordial despedida, Baeza se marcha, dice, «saboreando la emoción de haber estado en coloquio con uno de esos raros hombres cuyo encuentro es el más puro y secreto deseo de la cultura: un hombre al que poder llamar, en lo íntimo del corazón, maestro» ${ }^{25}$.

La misma pasión, el mismo «entusiasmo y fervor» lo impulsarán siempre a propagar un saber riguroso sobre figuras representativas de la literatura europea y occidental, como George Bernard Shaw, como John Keats, o Samuel Butler o Émile Zola o Léon Daudet, acerca de los que redactaría artículos luego recogidos por él mismo en sus volúmenes recopilatorios de los primeros años treinta. Se trata de escritos de circunstancias — propiciados por el estreno en España de una pieza teatral, la traducción de una novela o la conmemoración de una muerte- que nos ofrecen finas apreciaciones literarias hechas siempre desde el conocimiento amplio, cuando no exhaustivo, de la materia tratada.

\footnotetext{
25 «Una visita a André Suarès», en En compañía de Tolstoy, cit., p. 215.
} 
Prueban el interés de Baeza por toda novedad relevante y su vocación divulgativa y crítica, pero también nos dan idea de la riqueza del clima cultural en que se insertan y, sobre todo, nos permiten tomar el pulso de una vida literaria española que construye su modernidad con la mirada puesta en los valores europeos. El empeño de Baeza por la difusión de ese conocimiento sabría valerse de los canales de transmisión cultural más eficaces: el mundo editorial y el del espectáculo, la participación en iniciativas internacionales, asociaciones literarias, actos sociales, debates y conferencias, pero fue en la traducción y en la crítica donde su aportación tuvo mayor alcance. De aquella labor infatigable no todo ha quedado relegado al olvido: algunas de sus traducciones siguen circulando hoy por las librerías, y aunque apenas pueda decirse lo mismo de sus escritos y sean escasos los lectores que los conocen, mal se entiende sin obras como la de Baeza la dilatación, en las primeras décadas del siglo XX, de los horizontes hasta entonces muy angostos de la cultura española.

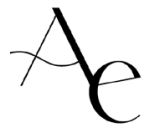




\section{BIBLIOGRAFÍA}

ANDERSON, Andrew A.: «Ricardo Baeza y el teatro», Anales de Literatura Española Contemporánea, XIX, 3 (1994), pp. 229-240.

_ _ "Una iniciativa teatral: Ricardo Baeza y su compañía dramática», en John P. Gabriele (ed.), De lo particular a lo universal. El teatro español del siglo XX y su contexto, Frankfurt am Main, Vervuert Verlag, 1994, pp. 29-40.

: «Coincidencias y paralelismos: las carreras teatrales de Ricardo Baeza y Cipriano Rivas Cherif», en Derek W. Flitter (ed.), Actas del XII Congreso Internacional de Hispanistas. Birmingham 1995, vol. IV: Del Romanticismo a la Guerra Civil, Birmingham, The University of Birmingham, 1998, pp. 41-49.

—_: «El primer lírico español contemporáneo: Ricardo Baeza, Federico García Lorca y el Romancero Gitano», Boletín de la Fundación Federico García Lorca, 13, 26 (2000), pp. 103-118.

—_: «La campaña teatral de Ricardo Baeza e Irene López Heredia (1927-1928): historia externa e interna de una colaboración», Revista de Literatura, 62, 123 (2000), pp. 133-153.

CADAFALCH, Cristina: «Per una bibliografia completa de Ricardo Baeza», Assaig de Teatre. Revista de l'Associació d'Investigació i Experimentació Teatral, 7-8-9 (1997), pp. 13-17.

CONSTÁN, Sergio: Wilde en España. Astorga: Akrón, 2009.

CREUS VISIERS, Eduardo: «Clasicismo, romanticismo y vanguardia en el ensayo de Ricardo Baeza», Bulletin of Spanish Studies, University of Glasgow, XCIV, 5 (2017), pp. 821-841.

GAGO RODÓ, Antonio: «Los ensayos de Ricardo Baeza: ideas sobre el teatro», Voz y Letra, X, 2 (1999), pp. 81-95.

GUTIÉRREZ CUADRADO, Juan: «Crónica de una recepción: Pirandello en Madrid», Cuadernos Hispanoamericanos, 333 (marzo 1978), pp. 347-386.

LAGET, Laurie-Anne: «La revue Prometeo et son traducteur Ricardo Baeza, deux média(teur)s culturels entre fin de siècle et poétique d'avant-garde», en Serge Salaün (ed.), Entre l'ancien et le nouveau: le socle et la lézarde, vol. 2, 2010, pp. 513-547.

LÁZARO, Alberto : H. G. Wells en España: estudio de los expedientes de censura (1939-1978). Madrid: Verbum, 2004. 
LÓPEZ MOLINA, Luis: «La literatura francesa en Prometeo», Boletín Ramón, 4 (primavera 2002), pp. 52-62.

ROMERO FERRER, Alberto: «De Araquistáin a Ricardo Baeza: La batalla teatral en la España de los locos años veinte», Assaig de Teatre. Revista de l'Associació d'Investigació i Experimentació Teatral, 42 (2004), pp. 181-194.

SALVAT, Ricard: «Primera aproximació a Ricardo Baeza», Assaig de Teatre. Revista de l'Associació d'Investigació i Experimentació Teatral, 7-8-9 (1997), pp. 9-11.

TOLEDANO MOLINA, Juana: «Ricardo Baeza (1890-1956): traductor y viajero», en Antonio Cruz Casado y Margit Raders (eds.), Estudios de Literatura General y Comparada. XVI Simposio de la Sociedad Española de Literatura General y Comparada, Lucena, Delegación de Cultura del Ayuntamiento de Lucena, 2009, pp. 521-528. 